Department of Business Administration

UZH Business Working Paper Series

(ISSN 2296-0422)

Working Paper No. 304

Project organizing as negotiation of (dis)ordering

Consuelo Vasquez

Dennis Schoeneborn

Viviane Sergi

27 August 2012

Work in progress: Please do not cite without the authors' permission

University of Zurich, Plattenstrasse 14, CH-8053 Zurich, http://www.business.uzh.ch/forschung/wps.html 
UZH Business Working Paper Series

\section{Contact Details}

\section{Consuelo Vasquez}

Université du Québec à Montréal, Canada

vasquez.consuelo@uqam.ca

\section{Dennis Schoeneborn}

University of Zurich, Switzerland

dennis.schoeneborn@uzh.ch

\section{Viviane Sergi}

Université du Québec à Montréal, Canada

sergi.viviane@uqam.ca

This paper has been presented at the $4^{\text {th }}$ International Symposium on Process Organization Studies, June 21-25, 2012, Kos/Greece. We also thank the participants from the Ourepo workshop at the University of Montréal as well as the $4^{\text {th }}$ workshop of the "Organization as Communication" $(\mathrm{OaC})$ network at the University of Hamburg for their valuable feedback. 


\title{
PROJECT ORGANIZING AS NEGOTIATION OF (DIS)ORDERING
}

\begin{abstract}
This paper proposes to study the constitution of organization at the interstice of order and disorder. By putting forward the processual, heterogeneous, and fragmented nature of organization, it explores the mediating role of communication in organizational becoming (Tsoukas and Chia, 2002). More specifically, the paper focuses on how organizations overcome the inherently precarious, contingent, and disorderly character of their existence in and through language use. Taking a communicative centered approach, the paper argues for considering language-in-use as intrinsically embedding both order and disorder. To do so it relies on the empirical material of three extensive qualitative case studies in three distinct project-based organizations: a science and technology diffusion program, a software development company, and a management consulting firm. The transversal analysis of these studies shows that efforts of ordering are continuously haunted by disordering, that is, the plurality of many potential orders, which are at work in communication. Furthermore, the analysis highlights the key and yet paradoxical role of ordering devices (in the three cases studied inscribed in texts), which are designed to create and maintain order, and because of their language-based nature, generate contingency and undecidability. Language is indeed a source of ambivalence (Weick, 1990). As such, the call for order can (usually does) trigger disorder and the other way around. Organizational agents must then beware of the spirits they call. As Goethe's (1797) sorcerer apprentice rapidly learns, what we animate, especially when associated to language, does always at some moment escape our command. Hence, we can never pretend to completely master it.
\end{abstract}

\section{KEYWORDS}

communication constitutes organizations (CCO), (dis)ordering, organizational communication, organization theory, process organization studies, project organizing 


\title{
PROJECT ORGANIZING AS NEGOTIATION OF (DIS)ORDERING
}

\author{
Und sie laufen! Naß und nässer \\ Wirds im Saal und auf den Stufen: \\ Welch entsetzliches Gewässer! \\ Herr und Meister, hör mich rufen! - \\ Die ich rief, die Geister, \\ Werd ich nun nicht los.
}

(Goethe, 1797)

Goethe's renowned poem Der Zauberlehrling - translated as the Sorcerer's Apprentice or the Pupil of Science - reveals a dramatic situation where the laws of nature are disrupted and thrown into chaos by the well-intentioned but inexpert apprentice's use of magic. In Walt Disney's popularized version of this poem, Fantasia (Walt Disney Picture, 1940), the apprentice (impersonated by Mickey Mouse) is nearly drowned by proliferating brooms - who were first useful tools in cleaning the sorcerer's laboratory - fetching buckets of water that become a torrential flood. The lines in which the apprentice implores his master to help him get things back to order, transcribed in the opening quote of this introduction, especially Die ich rief, die Geister, werd ich nun nicht los (literally, "The spirits that I've called, I cannot get rid of them anymore"), have been reinterpreted in various contexts (c.f. Internet and technology, Gregory, 2000; politics, Hossenfelder, 2008 ; law, Biermeyer, 2011) to describe a situation where a person summons allies that once set in motion, become independent and get out of control. In analogy to Goethe's poem, this paper addresses the (dis)organizing nature of organizations by exploring the spirits and brooms that are called to create order and yet, as the poem points out, tend to bring out disorder, at the same time. 
The question of order and disorder has been a common theme in defining organization. Conventional approaches in social science understand organization as means of ordering, structuring, controlling the chaotic world (e.g., Fayol, 1910; Taylor, 1911; Parson, 1951): organization is said to provide a sense of order to achieve stability, predictability and security. Such conception of organization is associated to a rational logic that sees the world as clearcut boundaries and categories, fixed meanings and singularities. In this view, order is what is classifiable, analyzable and accountable within a discourse of rationality (Chia, 1998). This traditional view is generally opposed to what Gouldner (1973) has named a "natural" model of organization. This model sees organization as an "intrinsic vagueness", where contingencies, change and situations are privileged; in other words, "where the disorderly is priced over the orderly" (Cooper, 1986: 168).

Whether the focus is on order or disorder, both views of organization see these features in opposite terms. However, as Paul Valery has suggested, "Two dangers continually threaten the world: order and disorder" (quoted in Cooper 1990:167). Organizations are no exception. Taking this premise as a starting point, we propose in this paper to study the constitution of organization at the interstice of order and disorder. In doing so, we follow recent development in organization studies associated to posthumanist and process-oriented theories (see Chia, 1998, Mol and Law, 2002; Tsoukas, 1998), which have initiated a radical reconceptualization of the relationship between order and disorder, putting forward the processual, heterogeneous, and fragmented nature of organization. Organization is then seen as "an unfolding process of tension between order and disorder that pluralizes and crossconnects artifacts and subjects”(Clegg et al, 2005: 154). Hence, to study organizations, researchers should focus on the "in-betweenness" (Cooper and Law, 1995) of organization and disorganization. That is, where dis/order(s) "come together and add up comfortably or in tension, or both" (Mol and 
Law, 2002:11). Following this perspective, we propose in this paper to study the emergence of organization in the balancing of order and disorder.

To do so, we draw on the concept of communication as the essential basis of our inquiry (c.f. Cooren et al, 2006) questioning how, through language-in-use, organizations overcome the inherently precarious, contingent, and disorderly character of their existence. Following a communication-centered approach - mainly inspired from the "CCO" perspective ("communicative as constitutive of organizations"; Ashcraft, Kuhn and Cooren, 2009) - we argue that organizations essentially consist of interconnected processes of language use and meaning negotiation that serve as a continuous source for both ordering and disordering (Kuhn, forthcoming). This statement is based on the acknowledgement that language naturally embeds both order and disorder: hence, processes of (dis)ordering are essentially communicative in character. In this sense, we propose to explore the (dis)ordering properties of communication at work in processes of organizing.

Our inquiry relies on the empirical material taken out of three extensive qualitative case studies in three distinct project-based organizations: a science and technology diffusion program, a software development company, and a management consulting firm. We have chosen project-based organizations as the setting for our study given that questions of order and disorder are particularly salient in this context: the overemphasis on projecting order to align actors and actions is usually confronted to the fact that projects typically emerge for a particular purpose and are temporary by nature; hence, they cannot draw on a given order from the past but have to reestablish order from scratch. The temporal punctuation of projects by milestones and the final deadline then allows to empirically perceive the very efforts of establishing (temporary) order. Our analysis shows that efforts of ordering are continuously haunted by disordering, that is, the plurality of many potential orders, which are at work in communication. Furthermore, our analysis highlights the key and yet paradoxical role of 
ordering (textual) devices, which are designed to create and maintain order, and still because of their language-based nature, generate contingency and undecidability. Language, as Weick suggests (1990), is indeed a source of ambivalence. As such, the call for order can - usually does - trigger disorder, and the other way around. Thus, organizational agents must then beware of the spirits they call. As Goethe's (1797) sorcerer apprentice quickly learns, what we animate, especially when associated to language, does always at some moment escape our command. Hence, we can never pretend to completely master the potential multiplicity of meaning.

The contributions of this paper are twofold. First, we contribute to reconciling a classical debate in organization studies concerning the orderly or disorderly nature of organizations. By following a non-dualistic perspective, we develop a conceptual and methodological framework to study the balancing of order and disorder as a key process in the constitution of organization. Second, our study contributes to the emerging perspective that grasps communication as constitutive of organizations $(\mathrm{CCO})$ by adding weight to the disorderly side of language use (cf. Cooren et al, 2011) and by showing how the CCO view can guide empirical inquiries into the essence of organizing. Specifically, by taking on the challenge to empirically explore the (dis)ordering properties of communication, we account for the ways language in use triggers order and disorder and how, by doing so, can be assumed to set the organization in motion, i.e. produce, maintain, or change it.

In what follows, we first depict the trends in organizational studies associated to an orderly and disorderly view of organization. We then present the communicative-centered approach and the key concepts on which our proposition relies. This allows us to further develop the non-dualistic vision of organization as (dis)ordering. The conceptual framework is followed by a brief presentation of the context of study and the methodology. From there, we move to the findings, which are based on three stories of (dis)ordering, each happening at 
a different moments in the life of the three projects we studied. The discussion reveals the similarities and differences of the cases, particularly with respect to the role of ordering devices and to the properties of language. We conclude with the contributions of our paper to organization studies, communication-centered approaches and project organizing.

\section{DEVELOPMENTS ON (DIS)ORDERING IN ORGANIZATION STUDIES: WHERE TO GO FROM HERE?}

As mentioned previously, the concern for order has a long tradition in organization studies. From Frederic Taylor's (1911) motion studies, to Henry Fayol's (1910) general theory of administration or Talcott Parson's (1951) theory of social system, classical organization theories have stressed the need for predicting and assuring the maintenance of order and control as paths to organizational stability and efficiency (Pina e Cunha and Gomes, 2003). Stemming from a rational logic, organization is here conceived as a system, based on control and stability, from which chaos has been - or needs to be - removed (Nonaka, 1988). As acknowledged by many authors (e.g. Clegg et al, 2005; Chia, 1996; Jeffcutt, 1994; Law, 1994), this traditional view of organization has dominated organizational studies and practices, permeating many subfields such as organizational learning (e.g. March and Olsen, 1975; Argyris and Schon, 1978), organizational change (e.g. Lewin, 1947; see also, Burners, 2004) or management engineering (Shenhav, 1999), to name a few. Recently, Ahrne and Brunsson (2011) have defined organizations as 'decided orders', emphasizing decision-making processes as the most fundamental aspect of formal organization through which rules, membership, sanction, and hierarchy are established.

However, other researchers have stressed the existence of divergence, instability, and contingencies in every organization. Implicitly or explicitly associated with topics such as 
complexity (e.g. Morin, 1973, 1986; Christensen and Cornelissen, 2011; Stacey, 1995), paradox, tension and contradiction (Brunsson, 2000; Smith and Lewis, 2011; Trethewey and Ashcraft, 2004), innovation and emergent design (Hatch, 1997; Weick, 1977; Burgelman 1983, Bygrave 1989), these ideas have challenged the traditional representation of organizations as orderly systems. Undoubtedly, chaos theory has been a major influence in triggering this paradigmatic shift (Thiétart and Forgues, 1995). Rooted in the study of natural systems, it has been translated in organization studies to describe the dynamic, open and nonlinear character of organizations.

In defining organization either as orderly systems or chaotic processes, these two strands of scholarship tend to oppose order and disorder, conceiving them as distinct states through which an organization moves (whether its from chaos to order or the other way around). Yet, as Clegg et al (2005) note, inspired by Serres (1982), "[o]rganization is the knot, the fold, where order and disorder meet" (p.154). Such a non-dualistic view implies that we need to consider organization as emerging in the "border zones, the grey area, where the collision of order and chaos, inside and outside, formal and informal, rationality and irrationality, structure and process occur" (p.155).

The work of Robert Cooper has deeply contributed to develop this non-dualistic understanding of organization (for a selection of his work, see Cooper, 1983, 1986, 1989, 1990, 2005; Cooper and Burrell, 1988, Cooper and Law, 1995). Cooper's thesis, stemming from a poststructuralist standpoint, presents dis/organization as the alternative to think about organization as social practice, rather than as a bounded thing in the world (Cooper, 1986; 1987; Cooper and Law, 1995). In his well-known 1986 article, entitled 'Organization/Disorganization', he strongly contests the 'illusionary edifice' (p. 317) of notions like structures and organizations as representing the foregrounding of unity and order 
where "what lies outside the system - or more accurately, what is said to lie outside the frame that creates the [organizational] system - is viewed as less ordered and less unitary than what is included" (p. 302). He elsewhere adds that when we think these terms, "[...] we miss the bigger question of how organization as generic process both structures and destructures our world, how our minds and bodies are caught up in its complex, reflexive dynamic" (1998:154). Organization as a process - which for him is the only way of thinking about organization - is constantly bound up with disorganization (Cooper, 1986). Hence, he calls for developing alternative explanations that can account for the "perpetual movement between order and disorder, between certainty and uncertainty" (Cooper, 1998:154). Cooper's ontology of organization/disorganization is, as Spoelstra (2005:108) aptly argues, where he "takes organization theory beyond organization theory" by stressing the interdependence and mutual constitution of order and disorder.

This call has been welcomed in organizational theory, mainly by poststructuralist and process-oriented scholars (see for example, the collection of essays in honor of Cooper, Chia, 1998, and more recently, Hassard, Kelemen, and Wolfram-Cox, 2008), who have explored alternative concepts and methodology in organizational analysis. Questions of reflexivity, multiplicities, and fluidity are some of the paths presented in these reflections for putting forward the processual, heterogeneous, and fragmented nature of organization. For instance, Law (1994) has coined the notion of "modes of ordering" to account for the multiple and never complete orderings through which an organization is told and performed. The focus here is on the (implicit) strategic process of alignment through which multiple and diverse narratives operate to generate complex social and material configurations (Law, 1992). As such, organization is seen as a non-coherent materially heterogeneous set of arrangements implicated by and implicating people and objects (texts, infrastructures, codes, physical devices, and so forth) (Law, 2001). 
Cooper's legacy, and more broadly poststructuralist philosophy, has been fruitful in disrupting traditional thinking and in generating new theoretical developments. In this paper, we pursue this line of inquiry by proposing to understand organizing as the balancing of order and disorder. This proposition is directly inspired by the work of Tsoukas and Chia (2002:580), who have argued that organizational becoming "occurs naturally, incrementally, and inexorably through 'creep,' 'slippage,' and 'drift' as well as natural 'spread."'. To exemplify their argument, they mobilize the image of the acrobat on the high wire. The acrobat, they argue, maintains her stability by "continuously correcting her imbalances (Bateson, 1979).” (2002:572, emphasis added). The beauty of her act - what makes the spectators hold their breath - is the 'illusion of order' that she creates, which requires indeed much energy, training, and repetition to be performed. What is true for the acrobat, as Tsoukas and Chia argue (see also Cooren et al, 2008, for a similar argument), also applies to organizations. Correcting imbalances - keeping order and disorder in-tension (Cooper and Law, 1995) - is a continuous activity in which organizational agents engage, in which they invest a lot of effort and energy. Moreover, the collective nature of this activity in the context of organizations heightens and amplifies the challenge of balancing. Keeping the balance is indeed a collective action, and as we suggest and put forward, one that is embedded in communication.

We believe that a communicative-centered approach can contribute both to the theoretical and analytical development of (dis)organization/(dis)ordering. We take this idea from Cooper himself (cf 1986), who has insisted on the inevitable plurality and instability of meaning as what motivates - meaning 'puts in motion' - organization. As such, opening to communication, as we develop in the next section, is an interesting avenue to ground this ontological and epistemological premise in the study of organizational processes, because of the intrinsic undecidability of language use that organize/disorganize social action. 


\section{EXPLORING THE (DIS)ORDERING PROPERTIES OF COMMUNICATION}

In this paper, in order to explore how (dis)ordering is negotiated in organizing, we focus on the constitutive force of communication (see Cooren, 2012). We argue that communication has a natural fit to the processual perspective that underlies our study (for example, see Strauss's notion of processual ordering, 1993), since processes of alternating between ordering and disordering are essentially communicative in character: they require the negotiation of meaning through language use. Hence, communication is not merely a vehicle of order and/or disorder, it is the fundamental process through which (dis)ordering is created, and thus organizing is constituted. We therefore argue that communication-centered approaches to organizing are particularly well-suited to bridge the dichotomy of order and disorder by highlighting that what tends to be presented as opposites are inherently intertwined (c.f. Smith and Lewis, 2011). Moreover, focusing on communicational events, which Cooren et al (2011:1151) have defined as "a segment of an ongoing and situated stream of socio-discursive practice (Schatzki, 2001, 2006)", seems particularly suited to account empirically and in practice for the central role language plays in the interdependence and mutual constitution of order and disorder (Cooper, 1990).

Communication-centered approaches to organizations have garnered considerable momentum in recent years (for a recent overview, see Cooren et al, 2011). Some of these works go as far as to emphasize the fundamental and constitutive role of communication for organizational phenomena (what has come to be called the CCO view; Ashcraft et al, 2009). Authors of this perspective claim that communication is not "simply one of the many factors involved in organizing, and it cannot be merely the vehicle for the expression of pre-existing 'realities'; rather, it is the means by which organizations are established, composed, designed, and sustained" (Cooren et al, 2011:1150). In other words, in this conceptualization, 
organizations essentially consist of interconnected processes of language use and meaning negotiation that serve as a continuous source for both ordering and disordering (Kuhn, forthcoming). In the following, we provide a brief overview of works from the CCO perspective, revealing that language-in-use naturally embeds both order and disorder.

In a processual understanding of organizations as organizing, Taylor and van Every (2000, 2011) depict organizations as being constituted by the continuous interplay of dynamic conversations (featuring high potential of disordering) and their materialization in textual form (i.e. somewhat ordered), e.g., in documents, templates, tools, or other artifacts. However, even though conversations may typically lean towards disorder and texts towards order, they do not inevitably correspond. Language can always bring both sides of the (dis)order distinction to the fore.

On the one hand, Cooren (2000), drawing mainly on ethnomethodology (Garfinkel, 1967, 2002; Heritage, 1984) and semiotics (Greimas, 1983), has highlighted the 'organizing properties of communication'. Essentially, he argues that language has many features that bring forth orders or meaning, e.g., through grammar, institutionalized turn-taking, recurrent narratives and storytelling. Taylor and Robichaud (2004) have lifted this observation to the ontological level: in light of the organizing properties of communication, they argue that each instance of language-use carries the seed for the potential emergence of organization to occur. In this view, organizations are imagined as multiple sites of ordering that get incarnated through interconnected processes of communication and their condensation in material form, e.g., through texts and other artifacts (Cooren, 2004; Kuhn, 2008, see also Robichaud et al, 2004).

On the other hand, scholars of the $\mathrm{CCO}$ view have also criticized an overemphasis on the organizing and ordering properties of communication (Bisel, 2008; Cheney, 2000, 2001); 
instead, these authors stress that communication can always form the basis for disordering to occur, as well (see Kuhn, forthcoming). This is also underscored by Cooren and colleagues: "If, as indicated above, communication is as much about the destruction and transformation of meanings as it is about their construction, $\mathrm{CCO}$ thinking should consider such questions relevant to its mission" (Cooren et al, 2011: 1160).

The destructive, transformative, and disordering nature of communication becomes salient, especially if we take the "polysemy" of language into account, i.e. in linguistic means the capacity of a sign to have multiple meanings in semantic field. The work of Weick (2001) has additionally contributed to acknowledge the potential of disorder, even chaos, in communication by studying how "frameworks and meanings destroy rather than construct one another" (p. 116). His well-known empirical analyses of the Mann Gulch or the Tenerife disasters exemplify dramatic events in which the lack of a collective sensemaking creates chaos and even destroys an organization. Considering this multitude of potential meanings, misunderstanding is seen here as the "normal case" of communication where a "full" or "correct" understanding is hardly ever reached (Luhmann, 1981).

Interestingly, in this view, it is especially the textual (i.e. rather than the conversational) form of communication that is prone to bring forth disorder. Due to the context-dependency of meaning (Ricoeur, 1981), when texts leave their initial setting of creation, they can become decontextualized and thus open up a vast contingency of potential interpretations (Spee and Jarzabkowski, 2011; see also Cooper, 1986); at the same time, they do not allow for instantaneous dissolving of misunderstandings, as conversations can do (Luhmann, 1992). In writing, we are trying to stop or to fix the meaning of the words we use, but the movement of language never stops; despite or in spite of all the efforts of the writer, language always overflows and escape from his control (Calás and Smircich, 1999). However, meaning is 
always on the verge of dissolution, of collapsing into confusion, as the made-absent term can always resurface. This echoes Derrida, for whom opposed terms should be conceived as sharing a totality and being engaged in a continual process of differentiation. To preserve the processual nature of this difference, Derrida coined the term différance ${ }^{1}$. Since both opposed meanings of a term cannot be used at the same time, one meaning has to be made absent; the (over)presence of one meaning is the result of this process that distinguishes and postpones to other meaning - which of course is only waiting for the opportunity to be revealed.

In Luhmann's conceptualization of organizations (2003), it is exactly the interplay between communicative processes of disordering and ordering that is grasped as the driving force of the organization's perpetuation. In his view, organizations face the continuous necessity of overcoming the precarious, contingent, and disorderly character of their existence in and through language use (that Cooren and his colleagues, 2011, referred to); in other words, if the continuous communicative negotiation processes of (dis)ordering come to an end, the organization also ceases to exists (Schoeneborn, 2011). Therefore, we find empirically in organizations multiple and recurrent episodes of communication that adopt to the form of decisions, i.e. they represent attempts of transforming open contingency (i.e. disorder) into fixed contingency (i.e. order) (Andersen, 2003; Nassehi, 2005). However, each instance of decision-communication merely establishes a temporary and local order that is accomplished on the expense of creating disorder and new contingencies at a later point in time or in different situational context.

1 In French, the replacement of the letter "e" by " $a$ " in différance can be understood as being closer to the idea of process, as in mouvance and partance, nouns that are built on verbs in the French form of gerund (mouvant, partantmoving, leaving). 
Taken together, these communication-centered works (Cooren et al., 2011) provide us with a rich theoretical framework that reconciles both ordering and disordering in the notion of communication as continuous meaning negotiation, i.e. as temporary accomplishments of (dis)ordering. Furthermore, the focus on communication opens up avenues for empirical investigations that further explore how the order-disorder nexus is unfolded in communicational events (Cooren et al., 2011) and jointly constitutes organizations. However, we need to consider the particular empirical challenge that the ordering properties of language use (cf. Cooren, 2000; Robichaud and Taylor, 2004) are typically clearer to observe than their disordering counterparts (cf. Bisel, 2008; Kuhn, forthcoming; for empirical studies on disordering see Collinsin, 1999; Doolin, 2003, Metiu, 2006, Yan and Panteli, 2011). Therefore, in this paper, we aim to start filling this void by introducing a language-centered methodology that is sensitive for disordering (in the sense of the creation of multiple meanings) and by putting it to use in a cross-case analysis of three studies in project-based organizations. The case settings, the empirical methodology, and the findings of our transversal analysis are presented in the next sections.

\section{METHODOLOGY AND CASES}

\section{Research context: Project-based organizations}

We have chosen to locate our inquiry in the context of project-based organizations (Hobday, 2000; Lindkvist, 2004), organizations that serve as sites of multiple and often parallel streams of project work. We consider project organizing as an ideal setting to study the dynamics of ordering and disordering because questions of order and disorder are particularly preeminent in these settings. On the one hand, a rational view of project organizing still dominates the field of project management, highlighting order not only as a desired outcome (e.g. Shenhar and Dvir, 1996) but as an imperative (Cicmil et al., 2009) for success. This prevalence of 
order is also present in the importance given to planning and control (Packendorff, 1995), and in the standard lifecycle model of projects (e.g. Lewis, 2002), where projects go through a succession of phases (from concept to closeout), in which disorder is expected to decrease. But, as some authors have exposed and denounced, this goes even further as the underlying model of action at the basis itself of mainstream project management and tools is rational, sequential, predictable and even standardizable (see, among others, Hodgson, 2002; Engwall, 2003; Clegg and Courpasson, 2004; Söderlund, 2004, 2005; Cicmil and Hodgson, 2006) - in other words, very much resting on order and ordering. Mainstream literature and investigations in project organizing therefore not only neglects disorder, but conceives it in a negative way, as something that threaten projects and that should be fought and eliminated. In this sense, disorder is delegitimized and remains as a blind spot in investigations of projects. Yet, practice-based accounts of project organizing reveal with great detail the inner complexities and disorder of project work in everyday activities (e.g., Levina and Orlikowski, 2009; Manning, 2008). Also, project's inherent temporariness (cf. Lundin and Söderholm, 1995) and the fact that they are typically punctuated by milestones and deadlines, they represent an appropriate context, empirically speaking, to investigate the continuous struggles of transcending disorder and accomplishing intermediate states of order. Taken together, these elements suggest that projects are a relevant setting to study how ordering and disordering coexist throughout project action.

\section{Approach: cross-case analysis}

Our study is based on the empirical material of three extensive qualitative case studies (Creswell, 1998) in three distinct project-based organizations previously and independently conducted: a science and technology diffusion program, a software development company, and a management consulting firm. A series of conversations between the three authors 
sparked the present inquiry. These conversations led us to recognize our common interest for the broad theme of order/disorder, and also that we each had empirical material that could be mobilized to illustrate the approach we are proposing here.

First of all, given the theoretical perspective in which our reflection is grounded and the questions we wish to investigate, in-depth qualitative research is the best-suited methodological approach to access and reveal the subtle dynamics of ordering/disordering. More precisely, although relatively uncommon (notable exceptions include Abdallah et al, 2011, Staundenmayer et al, 2002 and Tyre and Orlikowski, 1994), cross-case analysis of already conducted studies appeared as relevant in order to document a variety of a) project organizing, b) examples of interplay of ordering and disordering, and c) moments in the life of projects where such interplay could be particularly consequential. Before we began, we confirmed that it would be possible to compare material from the three cases. The three studies were compared along a number of dimensions: ontological and epistemological positioning, theoretical sensitivities, length of engagement with the field, presence of project organizing, nature of the material collected and possibilities of documenting ordering/disordering interplay.

After having established that our three cases presented enough similarities along these dimensions to be mobilized together in a new study, we proceeded to identify three key 'communicational events' (Cooren et al, 2011), one for each project, and each located at different moment in the course of the projects. Since projects are in constant transformation over their course, this anchoring in time allowed us to consider a diversity of project phases and concerns, especially with regards to the balancing of ordering and disordering. We also selected 'communicational events' that each included and involved in a notable way one ordering device, which in the three cases took the form of a text. The first case is therefore 
located at the initiation phase of a project where a proposal form serves as ordering device in a launching coordination meeting. The second case, is located around the project's mid-point; the ordering device is a functional analysis presented to solve an unexpected technical problem. The third case is located after the projects have been completed; the ordering devices take the forms of power-point presentations used as final narratives in a project database.

We limited ourselves to one 'communicational event' per case study, going narrower but deeper, in order to be able to show with great details both the interplay of ordering and disordering and its antecedents and consequences in the context of each project. Following this identification, we each develop one detailed vignette of the selected communicative event, which served as the basis for the analysis we present in the next section. But before we do so, we following next paragraphs briefly introduce the three studies in question, and the contexts in which they were conducted (Table 1 gives a general overview of the three case studies).

\section{INSERT TABLE 1 ABOUT HERE}

First case: Explora. The first case focused on the discursive and material practices through which a non-formal education program of the Chilean government, namely Explora, was able to transcend and perpetuate itself through space and time. This program aims to create a national scientific culture. To do so it develops and sets forth diverse initiatives (scientific camps, mobile expositions, visits to scientific laboratories, conversations with scientist), all of them organized around projects. Its major event, and the object of the study, is the National Science and Technology Week (hereafter, Science Week): an annual project offering a range 
of activities (science exhibitions, conferences, outdoor explorations, and so forth) for students and the educational community. Following an organizational ethnography approach, the data collection mainly consisted in shadowing (Czarniawska, 2007; McDonald, 2005) the different activities (several meetings, many phone calls, hallway conversations, "silent" work) and events related to the organization of this project in one of Explora's regional branch. During this three-month process, 172 hours of audiovisual recordings, 12 semi-structured interviews, a focus group, and many work documents (forms, electronic mail, posters) were collected constituting our empirical material.

Second case: Soft-A. The second case study focused on the social practices involved in the realization of a software development project, and on the contribution of materiality to this process of becoming, arguing for a definition of projects as sociomaterial arrangements. The study was conducted at Soft-A, a Montréal software development company, and focused on one of the company many concurrent projects, the Graph project. At Soft-A, all the work is done through project; consequently, many projects are conducted at the same time and employees are rarely involved in only one project. The Graph project consisted in the rewriting of an application used to produce graphics (named Graph) in one of the modules of Soft-A's main software. 22 meetings were observed, and 25 interviews conducted; more than 800 pages of documents were collected. Most of the meetings were dedicated to discuss the documents produced, with the exchanges happening during the meetings revolving around their content. More than half of all the documents generated during the Graph project were formal documents, documents whose production, use and circulation are mandatory at Soft-A. At Soft-A, these formal tools and procedures are appreciated, which differs from the low or the lack of use in practice of formalized methods and tools in software projects observed in other studies (Fitzgerald, 1998; Truex et al., 2000; Riemenschneider et al., 2002). 
Third case: $A B C$ Consulting. In the third case study, we examined to what extent the inherent processuality, contingency, and (dis)ordering of project work became visible in the aftermath of a project and beyond its boundaries (i.e. to organizational members who have not been directly involved in the project process). For this purpose, an ethnographic study at a multinational business consulting firm that has a special focus on developing IT-based solutions for their clients was conducted. The researcher worked for three months in the knowledge management department of the firm and had access to two company-wide electronic databases where consultants stored their project documentation in order to facilitate cross-project learning (cf. Ayas and Zeniuk, 2001). Based on a sample of 565 documents, drawn from the two databases in a randomized procedure, he analyzed to what extent organizational members who had not been involved in the project were nevertheless able to get an idea of the project's processuality and its inherent contingencies, i.e., how the project was executed, which paths were chosen, and which alternatives were taken into consideration. In addition, for contextualizing our findings, the researcher conducted 14 qualitative interviews with employees involved in project documentation.

In the following section we present our case findings through three vignettes, one for each project. The vignettes describe the communicational event under study focusing on how the balancing of order and disorder takes place in each organizational setting. It specifically addresses the role of the ordering devices in these cases, and points out particular (dis)ordering properties of language associated to them. Each vignette concludes with an analytical wrap-up, which will set the basis for the comparative analysis. 


\section{CASE FINDINGS}

\section{Case 1: “It had a blank page?!” When (potential) disorder motivates the call to order}

The first vignette deals with the initiation phase of Explora's Science Week project. As mentioned before, this project is Explora's major event, expected every year by Chilean's educational community. Because of its recurrence, the management of this project is part of an organizational routine that has been going on for the past the twelve years (at the time of the fieldwork) and that is inscribed in Explora's organizational practices. In this case, the projection of order is intrinsically associated to these past experiences, constituting a program of action that from year to year is being instantiated and routinized through a series of standardized practices and ordering devices. As such, the roles each organizational agent play, their actions and responsibilities, follow an orderly trajectory that is mainly defined by the project's history. However, as we will see next, despite this very ordered organizational context, (dis)orders (i.e. multiple 'other' orders) are always haunting the actualization of the program of action, threatening to destabilize it.

The following episode corresponds to one of Explora's regional branch kick off meeting with respect to the Science Week's coordination. This meeting takes place three months before the actual event, which is scheduled for the first week of October. In this sequence, Alejandra, the project manager and head of the regional branch, explains to Carla, the newcomer communication manager, the main orientations of the Science Week. More precisely, she describes the tasks associated to filling out the proposal form required by Explora's central committee for funding the project. This task is the first key step for starting the project, as it is mandatory for each regional branch to submit a project for the Science Week in order to receive the funding. The project is then studied by Explora's central 
committee for its acceptation or demand of modifications (generally the project is accepted, for this version, the amount solicited to Explora was fixed by central committee in advanced).

The proposal form is a twelve-page Word document sent by the central committee to each regional branch. It is structured around four sections: identification (the list of people and institutions responsible for the Science Week organization), program of activities (the list of activities proposed by the regional committee and those demanded by Explora's central committee), calendar of the activities (the overview of each activities and its schedule for the week), and budget (overview of the general budget and justification of the amount solicited to Explora). As we can see in figure 1 below, to complete each section, one must fill in the blank spaces in the tables to which specific items have been associated (for certain items specific indication about how to complete this section have been added, for example: "Must indicate the value per hour and the total for each person considered in this item.”). To some extent, we can say that the act of writing in the form is (materially) ordered by the tables and blank sections that call for completion.

INSERT FIGURE 1 ABOUT HERE

Furthermore, as the following communicational event illustrates, when mobilized in interaction the form is also ordering the dynamics of the meeting and, as the extended ethnographic study revealed, it the series of actions for coordinating the Science Week's regional project. As an ordering device, it is thus expected to accomplish what it was designed for: the projection of order through the inscription of tasks, responsibilities, goals, and deadlines. Interestingly, those who have designed it (the central committee), and those using it 
(the regional staff), share this expectation. Organizational actors rely on the form to order (and give order to) them. So when it fails to do so - or more precisely, when they anticipate it could fail - the reaction is one of surprise and astonishment. Facing (potential) disorder, a call to order is voiced. (The transcript is an English translation, since all interaction took place in Spanish. The passages in bold are the passages considered to be key for the analysis).

Alejandra: So, ok The subject of the National Science ahd Technology Week Besides, after this we will see the subject of the schedule for this week, aren't we?

Carla: $\quad$ Yes

Alejandra: Here is a copy of the form, ok ((She gives a copy of the form to Carla and then she starts turning the pages of her own copy))

Carla: $\quad Y e s, I$ would like you to explain this to me, because this is new for me, Alejandra.

Alejandra: Yes ((She is still looking at her copy)). Yes, but the form looks difficult, it's 15 pages but it's like a repetition over and over. Here, the only important thing is ((She looks at the first page of the form)), what we need is to put here the information of every...It had a blank page? ((She asks while looking at Carla's copy of the form and she looks at hers to see if she has a blank page too).

Carla: $\quad$ Yes

Alejandra: Oh! It probably slipped in there. Take it off.

Carla: So I take it off, that's it! ((She takes off the blank page)).

Alejandra: Hum, we need to put here the information of every member of the Network.

Carla: The Institutional Network?

Alejandra: Exactly. Ok, so, the first thing we have to know is when we are going to schedule the meeting for this Network (She looks at the calendar she has on her desk)

Carla: $\quad$ Yes.

Alejandra: That should be-We decided that Mondays =

Carla: $\quad=$ Monday afternoon.

Alejandra: So, next Monday.

Carla: $\quad$ Next? So on Monday this week.

Alejandra: Yes, OK? So I'd like you to do a formal invitation =

Carla: $\quad$ By email $=$ ?

Alejandra: Please email ((as she gives instructions to Carla, she always looks the notebook in which Carla is writing)). And then you have to follow up by telephone to confirm attendance. It is most important. And in the email, you ask them, explain that the meeting is to incorporate activities, incorporating the regional project activities of the week and then they bring in as specific as possible what activities they will perform. 
This excerpt highlights two interesting dimensions related to the (dis)ordering effects of the proposal form. The first one stems from the organizing dynamic to which Alejandra and Carla are participating, a dynamic that is guided by this document which, in a certain way, is telling what them to do. We can see how the order inscribed in the form, going from section one to four, and the call for completion are ordering the meeting. Alejandra starts the meeting by giving the form to Carla and from that point on, follows it page by page to orient the meeting and the subsequent tasks. For example, the first section in the form (identification) triggers in this meeting a specific task, which is oriented towards scheduling a meeting with the Science Week regional coordination committee, here called the Network. Now, what is important to note here is that these ordering effects are not simply consequences of the form's orderly presentation. They result from the collective efforts between Alejandra, mobilizing the form (both discursively and physically) and Carla, asking for explanations. The interactional dynamic of ordering, what we have called the balancing of order and disorder, is here at work. In trying to make sense of this document that "looks difficult", Alejandra and Carla engage in a negotiation of meaning where at the end of the sequence "the only important thing" for completing this section is to know when to schedule the Network's meeting. The ambiguity related to the complexity of a (blank) form is here partially removed: meaning is fixed in terms of what is key for them in order to fill out the form and thus, respond to the central committee's demand. Interestingly, while temporarily fixing the meaning of the form in this particular excerpt, in the following interactions during this meeting (but also in other interactional situation), the complexity of the form surfaces again. This questions the ordering effect of the form (what it was designed for), as for it to be filled in, it constantly requires interpretation, which then opens up to a multiplicity of meanings... and potential dis/orders, which directly points to the undecidability of language. 
The second interesting moment illustrated in this excerpt is related to the presence of an unexpected blank page. This seems, at a first sight, to appear as an insignificant and quick disruption - an error - in the course of action we have described before. Yet, if we take a closer look to understand Alejandra and Carla's reaction, we can see that the blank page, because of what it means in this particular situation where order is projected, is a real menace that calls for quick action. Let us note the genuinely surprise in Alejandra's question ("It had a blank page?"), which is followed by a plausible explanation (“it probably slipped there”), and a strict command ("take it off"). Note also that Carla does not question this command (nor the explanation) as she follows it and takes the page out (even if in practice the form that they will fill is a digital version and not the printed one they are using in this meeting). What is interesting to note here is their shared meaning on the 'illogical' presence of this blank page, while the form in its entirety is, as we have discussed before, built on blank spaces 'desperately' calling to be filled. One could ask, why then in such a con-text, this blank page seems out of place. The answer can be found in their sense of what the form is and what it is supposed to do in this context. As an ordering device, it helps them to textually fix meaning, but not any meaning and not in any matter. A complete blank page is, for them, just as mistake as its presence in the form is devoid of meaning.

When considering language, especially in its written form, a blank space, be it between words, sentences, paragraphs, has a specific meaning and function, which correspond to complex set of rules and convention. Spacing (i.e creating space) by separating words, letters, numbers, and punctuation, is here key for ordering. Yet, Alejandra and Carla's reaction reveals another dimension of the blank space: one that is not related to order, but on the contrary to (potential) disorder. In this sense we can say that the blank page is more than meaningless: it is dangerous. In fact, later on in this same meeting, when Alejandra will 
realizes she also has a blank page in her copy of the form, she will instantly take it off invoking the same explanation she did before: "there is a blank page that slipped in here".

The blank page in a form (that is required to be filled in) is dangerous because it calls for infinite possibilities of meaning. As such, it opens to contingencies and to dis/orders, which is by no means what the organizational actors are expecting the form to do in this particular moment of the life of the project. The spirits they have called to order and guide the program of action shows to be potentially creating disorder because of the multiple possibilities of divergent meaning. As Cooper (1986) recalls, no meaning (like the blank page) is intrinsically associated to excess of meaning. In discussing Marcel Mauss' notion of 'zero degree' - a process of no meaning, of no form, of absolute disorder, that pervades all social organization - he states the following: "The disorder of the zero degree is that which is essentially undecidable and it is this feature which energizes or motivates the call to order or organization" (p.321). As discussed before, the undecidability of language is here key to understand the threat of the blank page in this particular context. It shows how order and disorder can take place at the same time even when related to a device or tool that has been designed to order (and thus avoid disorder). Because this device is based on language, the (over)presence of multiple meanings (even in a space devoid of words) can always escape from our control. Therefore, as Luhmann argues (2003), because their existence in and through language use, organizations are always caught up in the dynamics of transforming open contingency into fixed contingency. Yet, complete order is never accomplished as new contingencies, at a later point in time or space, are created in trying to fix meaning. In this light, the blank page in the form (at the beginning of a project) is not only a potentially dangerous opening to contingencies, but a real one. The action to get rid of the blank page, as the interpretation of the form we discussed previously both illustrate the constant and never 
ending work of ordering, where fixing meaning and taking out (potential) ambiguity always bring disorder.

\section{Case 2: There's so much a text can do: when disorder and order slow down a project}

With this second case, we now move to the Graph project, zooming in on a situation that happened towards the middle of the project. At this point, most of the work on the new application's code has just been completed, and the team has put together for the first time all these sections of code, seeing the assembled result of their work. An unpleasant discovery awaits the developers: a part of the new Graph application does not work as expected; more precisely, the colors displayed in one window are off. Since the Graph application is used to produce graphics, this is a substantial issue. By trying to understand the root of this problem, the technical core comes to an uneasy conclusion: this situation challenges what had been decided at the beginning of the project. This surprise slows down the project: calling for a solution, the members of the technical core cannot readily move to the next planned step. This issue has to be solved, but from the moment it makes itself present, the team cannot fully rely on the order carefully assembled previously, nor on the course of action that the whole team had devised earlier. They work on finding the root cause of the issue, and in doing so, they come to the conclusion that it will be very difficult to overcome this obstacle. In other words, the irruption of an unplanned technical issue therefore "injects" an extra dose of improvisation in the project, by bringing in disorder where it was not expected. The members of the technical core develop a workaround solution, one that they find acceptable but that they know is not optimal. Before inscribing this solution in the new code, they have to obtain the agreement of the other members of the Graph team.

This proposed solution is written up and is presented through a document, called "document 52". This formal document (an already structured form that have to be filled during any project at Soft-A) is an ordering device, trying to recreate the previous alignment 
of project participants. As a formal document, whose completion is prescribed, document 52 will go in the archives of the company. While it serves the ongoing project, it will also be documenting for future use in other projects (see also case 3). This document is a template: it is already formatted, and the team members only have to fill it. More precisely, this document adopts the form of a "functional analysis", that is, a type of analysis that defines in details how the application will be working once it is realized. Functional analysis is usually written at the beginning of projects, and is the object of intense negotiation and alignment efforts: everybody on the team has to agree on the functionalities that will be developed. Once reached, this agreement allows the team to proceed. In other words, producing the functional analysis is more than a necessary step: it is an obligatory passage point. It is therefore unusual that a partly new functional analysis has to be written at this stage in the project. The solution exposed in document 52 opens up a discussion that is usually closed at this time in similar projects; in fact, it is rare that these discussions, which have to be opened and closed in the beginning of the project, are brought back at this stage.

Document 52 remobilizes what had been decided some months ago at the beginning of the project, it justifies why this previously agreed upon definition has to be revised, and proposes a new approach. The text is accompanied by images, projecting a view of what is proposed, as exemplified by figure 2 .

INSERT FIGURE 2 ABOUT HERE

What is particularly striking in the case of document 52 is the language it uses. The document presents "facts" about the situation: its tone is affirmative, neutral, and closed. 
Although the solution described in its pages is defined as "to be discussed", the language used implies inevitability: fundamentally, given the nature of the problem (which is only partially known), there is no other choice than this one - one that would end the story. In sum, document 52 can be read as an attempt at fixing, both in the sense of repairing and stopping: fixing meaning, fixing the problem, fixing the course of action. Yet, opting for a language that calls forth closure can be perilous, especially if this is done when the time is not ripe for closure and between two distinct worlds (understood here as set of concerns and priorities) taking part in the project.

In other words, document 52 reorders "on paper" the project (which it can do with a relative ease), but this reordering has to be discussed, negotiated and accepted; the technical aspects that caused this whole situation appear as tamed and realigned in the document, but the people taking part in the project still have to accept this solution. Circulation of document 52 therefore precedes a meeting, whose aim will be to discuss and validate this solution. In projects like Graph, two worlds have to meet: the world of clients, given voice to by clients' representatives, and the world of technique, represented by the members of the technical core. Because of this multiplicity of worldviews, negotiating meaning is a crucial practice in projects like this one. Usually, these two worlds are aligned once the functional analysis has been agreed upon; but in the face of the issue like this one with the colors, some of the bridging work between worldviews that had been done earlier in the project is lost, and this breach has to be (partially, temporarily) filled in. Negotiation of meaning has to happen once more - hence the meeting in question.

The meeting aims at approbating the reordering that has been proposed on paper, and during this meeting, the team members do work hard toward this goal. But "working hard" does not mean "in agreement": in fact, the discussion starts in quite an abrupt way: one client 
representative opens the discussion by saying - talking about the solution proposed by document 52 - : "I think it is unacceptable". This short line exposes the scope of the breach created by document 52 , which was in the first place an attempt to overcome the gap created by the issue with the new code. These five words say it all: the new order composed in document 52 is not approved and shared by all team members, and does not hold, despite the affirmative language that was used and the closure the document offered. The discussion that ensue is quite active and animated, and from this discordant note, a lot of clarifying work is done in the meeting: clarifying what is proposed, how the clients use the Graph application, what they will lose if they go with this option, other options... The discussion goes on for a while, and is followed by a moment of silence, when one senior member of the Graph project summarizes everything they are facing with another brief comment, limited to one word: "Disturbing" - which not only indicates that despite their best efforts, some element of mystery remains. It is in itself an interesting choice of words, referring directly to perturbation and to disorder - a disorder that still haunts quite tangibly the project.

At the end of the meeting, a partial agreement has been reached, but some elements are still left "hanging". The project members may understand better what may be causing this problem, but they have realized that can't reach a full resolution by themselves because other experts (the R\&D people) need to be involved to solve the technical issue that creates the colors problem. They would need new tools to address the issue, and these are developed by the R\&D people, which at the time when the problem arise, are quite taken by other important projects at Soft-A. What is particularly complex here for the Graph team is that all the puzzle pieces that have to come together are hard to reassemble at this precise moment: they have less and less time to finish their project, the "easy" solution the technical core proposes is not acceptable for clients, the perfect solution (the one that had been chosen at the beginning of the project) requires the help of experts who are not available... Therefore, at the end of the 
meeting, although the team members have made dissipated some of the disorder they were facing, to resolve in an acceptable way the color issue, the technical core will still have to explore other options. A partial reordering has emerged, enough for the project to be set in motion again. Disorder still characterizes the project after the meeting in question, but balancing it motivates the technical core to go forward, to look for and tinker with solutions, and even expands who has to be included in the project.

What we see with this situation, as in the previous vignette, is first this intertwinement of order and disorder, in which all agents, ordering devices and project members are involved. This vignette thus illustrates the collective and sociomaterial nature of (dis)ordering, revealing how it is through the assemblage of agents in interaction that balancing of order and disorder can be achieved. As this case shows, even if the ordering device used first "backfires" on the team, its insertion in the course of the project and what occurs through interactions after its circulation are enough for the project to continue to move on. The sense of order may be partial, elusive and fragile as it is in this case, but maybe this is enough to keep the project going on. Therefore, ordering can never be strongly assigned to ordering devices, as a) they can only generate a limited sense of order and b) by being knitted with language, they necessarily embody - despite all the best efforts! - its inherent polysemy. In this sense, document 52 can be interpreted as having "failed" in reestablishing a sense of order because of its language and its timing: indeed, by choosing to perform a conversation of closure (Ford and Ford, 1995, Ford, 1999) before meaning had been shared between the technical core and the clients' representative, the chances for closure to really happen were thin. As Ford and Ford underline, "Closure [...] involves both a letting go of what no longer works and a continuation of what does." (1995:551), and thus invokes an acknowledgement. But as we see here, to have the desired effect, this acknowledgement has to be shared, and it is this sharing that was the missing ingredient in this situation. Too much was excluded by this text, yet the 
clients' representative saw through the text: the note on which the meeting started can be seen as echoing the intensity of the closure displayed in document 52. Following Cooper's contribution, we see here that reducing disorder by imposing order therefore created a different form of disorder. Undoubtedly, a different language, one evoking more potentiality, conditionality and exploration would have led to a different sequence of (dis)ordering, but not necessarily one involving less negotiation, and this stems from the undecidability of language: complete closure can never be expected. Also, because of contextual elements (including the harmony of the Graph team, and their level of experience in doing projects of this kind), what we described here did not fully stop the project. In other settings, incidents like this one excluding too much and closing too early in an attempt to restore order quickly - can be deeply consequential, perturbing on a large scale a project's course of action.

\section{Case 3: What you see is not really what you get! Ellipses and the illusion of order}

The third study featured the analysis of two cross-project learning databases in a multinational consulting firm, $\mathrm{ABC}$ Consulting. These databases were set up following the objective to share experiences and the knowledge gathered in individual projects also beyond the specific context of the project. Hence, for this purpose, consultants were required to submit electronic documents to the database that allowed for this kind of cross-project knowledge exchange. Given the retrospective character of the documentation practices at $\mathrm{ABC}$ Consulting, case 3 is particularly suitable to cover the finalization and post-hoc reconstruction of a project's process. Our analysis of the documentation practices (plus complementary interviews) aimed to answer the question to what extent the documents that report about past projects invoke the impression of a consistent and orderly project process or to what extent do they also - and as well - allow for glimpses into the disorderly side of project processes. 
The analysis showed that, even though the databases were set up with the aim to foster the learning value from projects, usually all that remains after a project has been completed is a collection of highly condensed summaries in the form of PowerPoint documents (cf. Yates and Orlikowski, 2007), many of which could not be put easily into context retrospectively by the consultants. Furthermore, the narratives contained in those documents were primarily focused on merely presenting final results and thus foregrounded consistency and order (e.g. by highlighting "best practices" or "success stories"); to the contrary, they masked the contingency and disorder of the project process (which would have been expressed as doubts, mistakes, or alternative paths). In this regard, the internally shared documents simply equaled most typically the final project deliverables to the client.

What is more, the most frequent document type in the databases were so-called "one page citation" documents, i.e., PowerPoint presentations where the accomplishments of a past project were summarized in a standardized format ("What issues did the customer face?"; "What solution did [the consulting firm] provide?", and "What were the results?") on one slide only. As the interviews revealed, these slides were used primarily as included in acquisition presentations - in order to impress potential clients by providing extensive evidence of previous consulting experience in a particular business area or industry. Naturally, these documents strongly favor to present past project on a narrative of order rather than disorder - independent from how messy the process of conducting the project might actually have been.

The PowerPoint documents of this type, however, can be seen as the final products of the ongoing, day-to-day practices by the consultants to create a clean, neat, consistent and orderly presentation of what happened in a project (primarily for the client and typically held in form of PowerPoints). As the interviewees reported, this was done practically by going 
repetitively over the PowerPoint documents and "polishing" each slide. For instance, this meant to reduce the content of slides in order to arrive at the main essence. More experienced consultants (e.g., the project leader) would typically ask junior consultants to use bullet point lists instead of longer elaborations and to leave out as many words as possible (e.g., "don't use more than three lines of words per bullet point") in order to carve out the "key message". Figure 3 shows a typical example of a "polished" PowerPoint slide. As the figure exhibits, the bullet points consist of a couple of words or fragments of sentences only and, therefore, pose particular challenges to their future recontextualization.

\section{INSERT FIGURE 3 ABOUT HERE}

In terms of language use, this rhetorical strategy can be termed as the ellipsis. Ellipses refer to the omission one or more words from a phrase whereas the omitted word would normally be required by the remaining elements. Interestingly, however, while the ellipsis can represent a powerful rhetorical strategy in a face-to-face presentation in a given project setting (where project members can activate their contextual knowledge and fill in the blanks), in the decontexualized setting of cross-project communication (i.e. in the databases that are accessible to the entire project-based organization), this very effort of ordering results in a rather disorderly situation: because of less words and more blanks to fill-in, meaning was less clearly defined what opens up a wide range of possible interpretations of meaning (the disorderly side of language use). Accordingly, one interviewee, a consultant, expresses his disappointment regarding the lacking usefulness of the cross-project learning databases: "So far we have been creating a pile of documents in the databases, but these are not [...] put into context at all." However, instead of tracing the lack of contextuality back to the PowerPoint 
genre's inherent characteristics (cf. Tufte, 2003; Yates and Orlikowski, 2007), the employees of $\mathrm{ABC}$ Consulting tend to attribute the databases' shortcomings to a lack of standardized procedures for "quality assurance":

The project profiles [in the cross-project learning databases] certainly had a problematic status right from the start because their content was not validated in terms of quality. [...] This is how a lot of 'trash' entered the database. (Interview statement by KM support member)

Taken together, and seen from a process perspective (e.g., Tsoukas and Chia, 2002), these databases rather seem to represent the 'cemetery' of project work; in other words, the entire processuality and disordering which was unfolded during the course of project, became buried in textuality after the project came to an end. However, importantly and similarly to our first two cases, it was the very same process of ordering, i.e. by leaving out words and contextual meaning (rhetorical figure of the ellipsis) when creating a PowerPoint presentation in the context of a project (e.g., a final presentation for the client), that created disorder and contingency, at the same time, i.e., as soon as it left the project-specific context and entered the cross-project level. In other words, the text gained a 'life on its own' (Cooren, 2004) and extended well beyond the control of meaning by its creators (Kuhn, 2008). Consequently, consultants simply lacked contextual cues for being able to recontextualize what had happened in the project (cf. Spee and Jarzabkowski, 2011).

\section{DISCUSSION}

The three vignettes presented previously tell us three distinct stories of (dis)ordering in the context of project work. These (dis)ordering stories put forward the collective efforts that made by organizational agents in keeping the project in motion (especially in case 1 and 2) and alive (especially in case 3 ). We have seen in each case that to do so, organizational agents engage in what can be described as an acrobatic and dynamic balancing order and disorder: correcting imbalances and sometimes creating them in order to keep the project going on. In 
looking closely at this collective dynamic, taking here as Tsoukas and Chia (2002) suggest, a performative view on organizational becoming, we have showed that order and disorder are intertwined even in (supposedly) very orderly contexts such as project organizing. Furthermore, our cases show what Cooper $(1986,1990)$ has repeatedly emphasized: order and disorder are not in opposition, but mutually constitutive: order can come out of disorder, and the other way around. They can even co-exist at the same time, because one is always haunting the other. The three vignettes illustrate this presence/absence dynamic and more importantly how this dynamic is key in triggering action, be it at the beginning, the middle or the end of a project. Interestingly, in each case the dynamic of order/disorder is different, showing multiple configurations of the order/disorder conundrum. Table 2 summarizes the comparative analysis of our three cases focusing on the three dimensions that will be discussed in this section.

\section{INSERT TABLE 2 ABOUT HERE}

In the first case, the anticipation of potential disorder (in the incident of the blank page) and the complexity of the ordering device (the blank form), trigger a call to order, which is translated in the actual situation in fixing the meaning of the form ("the first thing we need to know") and removing the potentialities of multiple meanings by taking out a blank page. Disorder is, in this case, threatening the projection of order that is needed to launch the project. As a ghost, it is haunting the actual situation and thus triggers a sect of actions and re-actions that attempt to remove contingencies (even if, as showed, this is never possible). In the second case, a disruptive event triggers a call to order, which results in a functional analysis 
(document 52). Yet this analysis once presented in a meeting to the whole project team is contested and disorder appears.

During this meeting, two worldviews are confronted and a negotiation revolving around the technical problem and the proposed solution emerges. Finally the team arrives to a compromise: order is partially achieved, yet other issues are left opened...the ghost of disorder is still haunting. The third case shows a final attempt to polish disorder in the creation of concluding narratives of different projects, all presenting success stories. Disorder is here polished, almost evacuated, in a neat and standardized PowerPoint presentation that reveals retrospectively an orderly and smooth process of organizing. Yet, this overly ordered (thus, dead) image of the project is actually hiding contingencies, i.e. disorder, which, however, re-enter as soon as the document becomes shared in the cross-project context (i.e. the knowledge management databases)

Attempts of ordering are striking in all cases: organizational actors do indeed put a lot of efforts in creating order(s). But, as our analysis suggests, this order is only temporary and partial: ordering is never completed. It is indeed a precarious and fragile process (Law, 1994, 1992). In a sense, we could say, relying on our cases, that what organizational actors create is an illusion of order - akin to what the acrobat does when walking on the high wire -, one that allows them to move forward, even if it is just for a moment and in a particular situation. If a complete and durable order were to be created, then movement would stop (things would be fixed; the acrobat would have fallen down). At the same time if no temporal, partial (even if illusionary) order were ever achieved, as in a continuous state of disorder, then the organization would similarly be paralyzed. Paul Valery's quote takes here its full meaning. Indeed, order and disorder independently threaten the world (i.e. the organization). But if we acknowledge their interdependence and mutual constitution, then we can understand that 
order with disorder is, we could say, what makes the world go round: what creates movement and thus constitute organization. Taking this non-dualistic positioning changes our perspective on organizing, which, as mentioned previously has traditionally been associated to order and stability. It acknowledges the acceptance of some form of dis/order(s) as an intrinsic and inevitably characteristic of social reality. Hence, the core issue to investigate shifts from questioning how a social order is created, to how plural orders (Law, 1992) cohabit: how order and disorder are intertwined - in our words, balanced.

Our analysis offers two related answers to this last question. The first one deals with the collective and hybrid performance of balancing order and disorder, in which a plenum of agencies (Cooren, 2006) are involved in this acrobatic act. In our empirical illustrations, we particularly focused on the role of ordering devices, which incarnated in standardized texts and on which organizational actors relied to 'create a sense of order'. Related to these textual ordering devices, the second part of the answer acknowledges the key role communication plays in creating both order and disorder, and thus, as we argue, in constituting organization. We will now discuss these two issues in the light of what we have learned from our study.

As mentioned previously, our cases deal with collaborative and collective efforts to organize a project. In the three cases, therefore, collective action aimed to constitute a project. A common and key aspect in each case was the role of textual ordering devices for projecting order (case 1), accounting for and reacting to disorder (case 2) and polishing disorder (case 3). In all cases, organizational actors strongly relied on these documents to fulfill their goals: launching the project (case 1), solving an unexpected problem (case 2), closing a project with a success story (case 3 ). Interestingly and despite their highly standardized form (all three documents were based on templates) - these formal tools initially designed to control, align and order action, were opened to contingencies and ambiguities once put in their context of 
use... contingencies and ambiguities which in many respect were created by them. It is here that the image of the sorcerer's apprentice, with his spirits and his brooms, becomes useful to understand how this socio-material assemblage, supposedly composed to create (some kind of) order, gets completely out of control. In our cases, the brooms represent the ordering devices in which our apprentices, the members of the project teams, are relying on: they created them, they mobilize them, they question them. Now, these devices, as we have emphasized, have a peculiar characteristic: they are textual documents, thus made with written language. As such, and because of the intrinsic polysemy of language in use, they fundamentally escape from the control of our apprentices. We must underline that this is not because the project members are in the state of learning the magic spells and moves to become great magicians (i.e. project organizers apt at imposing order), but because we can never completely master language and its multiplicity of meanings. We here come back to a shared idea in communication scholarship, more precisely in linguistic and semiotics, that has been put forward by researchers such as Saussure (1974) and later on by Derrida (1968). This common idea stands on the basis that "in language they are only difference"(Saussure, 1971:114), which means that language is a system in which each term or sign is defined by other terms from which it differs. Language is incomplete and based on difference, "on what it is not" (Cooper, 1986: 309). Hence, far from fixing sign as meaning, language always opens up to a plurality of differential meanings. Being sensitive to the properties of language helps in understanding how the work of balancing order and disorder unfolds, and such a sensitivity, as our analysis suggest, may be a way to better accomplish a work that will anyway have to be perform, if any form of organizational action is to go on.

In each case, we focused on a particular aspect of language that 'in action' illustrated this opening to plurality, of dis/order(s). Case 1 focused on the role and effects of blank spaces in a template (blank spaces in table and a blank page). Here, we highlighted the 
ambiguity of what is considered to be a writing and typographic convention, were space is related to a blank area devoid of meaning which creates ordering (i.e. inter-words, intersentences, etc.). In the analyzed situation of interaction, the blank area in the tables was interpreted as an area to fill with specific information. Yet, the blank area in a (unexpected) page was rather interpreted as an error and moreover as a threat to ordering. The event related to the blank page illustrates well the differing dynamic where the meaning of an empty space conveys its differential (a space full of meaning), and triggers action. In case 2, the focus was on statements of closure which, when used 'in the wrong place at the wrong moment' created the opposite of what was expected through them. These statements opened up to questions, contestations and resistances, bringing in polysemy and confusion via the unilateral message that the proposed solution conveyed. Closure involves shared meaning on what to let go of and on how to continue (Ford and Ford, 1995). However, as the analysis shows, to reach such a shared meaning, one needs to open up (not close) to other plausible ways in order to arrive to a solution. By proceeding otherwise, the ordering device could only awake disorder, which was revealed and had to be dealt with during a face-to-face interaction. Finally, case 3 focused on the role of ellipsis in PowerPoint presentations. Ellipsis, the omission of one or more words from a phrase, is here used as a rhetorical strategy to highlight the key notions and ideas that will be then completed in a face-to-face presentation. However, as the case shows, in the decontextualized setting of cross-communication (which is usually the case in organizations), this effort of ordering results in a disorderly situation, where the lack of meaning opened toward lack of clarity and presence of a wide range of possible interpretations of meaning. This case particularly highlights that the disorderly side of language can also happen in different times and places. When contextual cues for recontextualizing meaning are missing, disorder (i.e. many other orders) appears in its clearest (and potentially most threatening) way. 
We have discussed in our cases how the undecidability of language is at work when mobilizing and trying to make sense of ordering devices. Our cases reveal that it is an impossible task to present a unilateral and unequivocal message, as meaning is always on the verge of dissolution, of collapsing into confusion, because of the differing terms that haunt the message. Furthermore, our cases illustrate that the textual form of these ordering devices enhances, to some extent, the ambiguity and polysemy of language. While written language is usually conceived as a efficient form to fix meaning in a text (Chia, 2001), our cases show that once created and delocalized from the context of its creation (mobility being a key characteristic of texts), it detaches itself from the writer, having a life a its own and thus escaping of the writer's control. This echoes in a way Derrida's (1988) notion of restance, a concept he uses to designate relative permanent effect of discursive devices, which goes beyond the context of their creation and the acts of their creator. As such, texts can be conceived as key agents (i.e having agency, c.f. Cooren, 2004) that drive (dis)organizing processes. This proposition questions the definition of organizational texts not only as formal tools for ordering but also as functional language generate by organizational agents to accomplish something (Taylor and Robichaud, 2004). Both conceptions of organizational texts stem from an ordering view of organizing, which allocates ordering effect to discursive/textual forms, consequently delegating the effect of disordering to conversation, negotiation and interaction. Our analysis instead shows that texts can be source of disordering because of their inner capacity to 'jump around' and thus to trigger different interpretations in different places and times. Let us recall what the brooms were capable of when the apprentice lost his control over them: fetching buckets over buckets, they nearly drowned the apprentice in a torrential flood. Beware of the spirits you call... as language can never fully be mastered! 


\section{CONCLUSION AND OUTLOOK}

In this paper we proposed to study the constitution of organization at the interstice of order and disorder. By putting forward the processual, heterogeneous, and fragmented nature of organization, we explored the mediating role of communication focusing on how organizations overcome the inherently precarious, contingent, and disorderly character of their existence in and through language use. Taking a communicative centered approach we developed a conceptual and methodological framework to study the balancing of order and disorder in language-in-use. Focusing on the (dis)ordering properties of communication in the context of project-based organization we showed how ordering and disordering seem to jointly constitute the communicative entity we call organization (cf. Cooren et al., 2011; Kuhn, forthcoming).

The contribution of our paper is twofold. First, we contribute to reconciling a classical debate in organization studies. Previous works have rather emphasized either the orderly (c.f. Taylor, 1911; Parson, 1951; Arnhe and Brunsson, 2011) or the disorderly (c.f. Thiétart and Forgues, 1995; Putnam, 1986; Hatch, 1997) nature of organizing. Instead, we have proposed here to apply a non-dualistic perspective that highlights the inherently intertwined nature of practices of disordering and ordering that jointly constitute organization. Crucially, our crosscase analysis of project-based organizing from three organizations showed that the very efforts of organizing created disorder at the same time. Hence, from a processual perspective (e.g., Tsoukas and Chia, 2002) organizing is a matter of balancing out order and disorder rather than favoring one over the other. Furthermore, by adopting a communication-centered perspective on organizations (Cooren et al., 2011; Luhmann, 2003; Taylor and Van Every, 2000), we were able to identify specific linguistic mechanisms that bring forth (dis)order (i.e. a co-existence of order and disorder). Our case studies showed that in each phase of project 
organizing, rhetorical and typographic practices were at play (e.g., the blank page, statements of closure and use of bullet point lists in PowerPoint) that aimed at eliminating disorder in the favor of order. All of these practices involved the textualization and fixation of meaning at one point or another (Cooren, 2004; Kuhn, 2008). However, as it is a general feature of language use, the fixation and control of meaning in one context does not ensure a complete mastery of all its potential meanings, especially as soon as the text extends beyond the specific context of its creation (Ricoeur, 1981).

Second, our study contributes to the emerging perspective that grasps communication as constitutive of organizations (CCO) (Ashcraft et al., 2009; Cooren et al., 2011). Within this line of thinking, we follow recent calls to not only emphasize the ordering properties of communication but also its disordering properties, when applying a communication-centered lens on organizations (e.g., Bisel, 2008; Cooren et al., 2011; Kuhn, forthcoming). For this purpose, we have mobilized works from scholars like Cooper (1986), Luhmann (2003), or Ricoeur (1981) that have been only very recently acknowledged as important influences in CCO thinking (for Luhmann: Cooren et al., 2011; Schoeneborn, 2011; for Ricoeur: Spee and Jarzabkowski, 2011; for Cooper: Kuhn, forthcoming). Our findings can be seen as further evidence for our theoretical argument that in language use, both ordering and disordering are fundamentally entangled (i.e. striving for ordering and the control of meaning typically creates disorder, at the same time). By emphasizing the disorderly side of language use, these works enable the CCO perspective to broaden its perspective and to account for paradoxical phenomena of (dis)ordering that are genuine to language use, as we have argued in this paper. What is more, our cross-case analysis represents one of the first empirical works that combines theoretical ideas from these various streams of $\mathrm{CCO}$ thinking (see Cooren et al., 2011) and shows their usefulness in guiding the empirical analyses. 
Finally, we also want to shed light on one potentially fruitful avenue for further inquiries into the phenomenon of (dis)ordering. Interestingly, when we theoretically approached the phenomenon of (dis)ordering, we mobilized the metaphorical figure of the acrobat, balancing out order and disorder. The empirical analyses, however, rather evoked the figure of the sorcerer (or, more precisely, his apprentice) who cannot master the disorderly spirits that he called - in the aim to create order. However, it is important to note that both metaphorical figures, the acrobat and the sorcerer, originate from the same metaphorical domain, that is, the circus (Parker, 2011). Evidently, the day-to-day coping with (dis)ordering in organizational settings shares many characteristics with practices at play by artists in a circus (e.g., skillfulness, storytelling, entertainment, illusion, etc.). Hence, we believe it can be worthwhile to further explore the aptness and heuristic value of the metaphorical domain of the circus (for methodological considerations, see Cornelissen, 2006) for studying practices of (dis)ordering in organizational settings. 


\section{REFERENCES}

Abdallah, C., Denis, J.-L., and Langley, A. (2011). Having your cake and eating it too: Discourses of transcendence and their role in organizational change dynamics. Journal of Organizational Change Management, 24(3), 333-348.

Ahrne, G. and Brunsson, N. (2011). Organization outside organizations: The significance of partial organization. Organization, 18(1), 83-104.

Andersen, N. A. (2003). The undecidability of decisions. In T. Hernes, and T. Bakken (Eds.), Autopoietic organization theory: Drawing on Niklas Luhmann's social systems perspective (pp. 235-258). Oslo: Copenhagen Business School Press.

Argyris, C., and Schön, D. A. (1978). Organizational learning. Reading, Mass: AddisonWesley Pub. Co.

Ashcraft, K. L., Kuhn, T. R., and Cooren, F. (2009). Constitutional Amendments: "Materializing” Organizational Communication. Academy of Management Annals, 3(1), 164.

Ayas, K., and Zeniuk, N. (2001). Project-based learning: Building communities of reflective practitioners. Management Learning, 32(1), 61-76.

Bateson, G. (1979). Mind and nature. Bantam. Toronto. Canada.

Biermeyer, T. (2011). From the Spirits that I Called - the Conflict between Domestic Norms and Internal Market Law in Dutch Social Housing Policy. Maastricht Faculty of Law Working Paper No. 2011-5. Available at SSRN: http://ssrn.com/abstract=1806944 (last accessed on May 28, 2012)

Bisel, R. S. (2008). The (dis)organizing property of language: error and inefficiency in coordinated action. Unpublished dissertation, University of Kansas.

Boden, D. (1994). The business of talk: Organizations in action. London: Polity Press. 
Brunsson, N. (2000). The irrational organization: Irrationality as a basis for organizational action and change, 2nd edn. Bergen, Norway: Fagbokforlaget.

Burgelman, R. A. (1983), "Corporate Entrepreneurship and Strate-gic Management: Insights from a Process Study," Management Science, 29, 12, 1349-1364.

Burnes, B. (2004), Kurt Lewin and the Planned Approach to Change: A Re-appraisal. Journal of Management Studies, 41: 977-1002.

Bygrave, W. D. (1989), "The Entrepreneurship Paradigm (II): Chaos and Catastrophes among Quantum Jumps?" Entrepreneurship: Theory and Practice, 14, 2, 7-30.

Calás, M. and L. Smircich (1999). Past postmodernism? Reflections and tentative directions. Academy of Management Review, 24(4):649-671.

Cheney, G. (2000). Interpreting interpretive research: Toward perspectivism without relativism. In S. R. Corman, and M. S. Poole (Eds.), Perspectives on organizational communication: Finding common ground (pp. 17-45). New York: Guilford Press.

Cheney, G. (2001). Book review: The organizing property of communication. Quarterly Journal of Speech, 87, 453-455.

Chia, R. (1996) Organizational Analysis as Deconstructive Practice. Berlin: Walter de Gruyter.

Chia, R. C. H. (1998). In the realm of organization: Essays for Robert Cooper. London: Routledge.

Christensen, L. T., and Cornelissen, J. (2011). Bridging corporate and organizational communication: Review, development and a look to the future. Management Communication Quarterly, 25(3), 383-414.

Cicmil, S. and D. Hodgson (2006). Making projects critical : an introduction. In D. Hodgson and S. Cicmil (eds). Making projects critical. Basingstoke [England], New York: Palgrave. 
Cicmil, S., Hodgson, D., Lindgren, M. and Packendorff, J. (2009). Project management behind the façade. ephemera, 9(2): 78-92.

Clegg, S. and D. Courpasson (2004). Political hybrids: Toquevillean views on project organizations. Journal of Management Studies, 41(4): 525-547.

Clegg, S. R., Kornberger, M., \& Rhodes, C. (2005). Learning/becoming/organizing. Organization, 12(2), 147-167.

Cooper, R. (1983) 'The other: a model of human structuring', in G. Morgan (ed.), Beyond Method. Beverley Hills: Sage.

Cooper, R. (1986). Organization/disorganization. Social Science Information, 25(2): 299-335.

Cooper, R. (1989). Modernism, postmodernism and organizational analysis 3: The contribution of Jacques Derrida. Organization Studies, 10(4): 479-502.

Cooper, R. (1990). Organization/disorganization. In J. Hassard \& D. Pym (Eds.), The theory and philosophy of organizations (pp. 167-197). London: Routledge.

Cooper, R. (1998) 'Assemblage notes', in Chia, R. C. H. (eds), Organized Worlds Explorations in Technology and Organization with Robert Cooper. London: Routledge.

Cooper, R. (2005) ‘Relationality’, Organization Studies, 26 (11): 1689-1710.

Cooper, R. and Burrell, G. (1988). Modernism, postmodernism and organizational analysis 1: An introduction. Organization Studies, 9(1): 91-112.

Cooper, R. and Law, J. (1995). Organization: Distal and proximal views. Research in the Sociology of Organization, vol. 13, Greenwich, CT: JAI Press, pp. 237-274.

Cooren, F. (2000). The organizing property of communication. Amsterdam: John Benjamins.

Cooren, F. (2004). Textual agency: How texts do things in organizational settings. Organization, 11(3): 373-393. 
Cooren, F., Taylor, J. R., and Van Every, E. J. (2006). Communication as organizing: Practical approaches to research into the dynamic of text and conversation. Mahwah, NY: Lawrence Erlbaum Associates.

Cooren, F., Brummans, B. and Charrieras, D. (2008). The coproduction of organizational presence: A study of Médecins Sans Frontières in action. Human Relations, 61(10), 13391370.

Cooren, F., Kuhn, T. R., Cornelissen, J. P., and Clark, T. (2011). Communication, organizing, and organization: An overview and introduction to the special issue. Organization Studies, 32(9), 1149-1170.

Cornelissen, J. P. (2006). Making sense of theory construction: Metaphor and disciplined imagination. Organization Studies, 27(11), 1579-1597.

Creswell, J. W. (1998). Qualitative inquiry and research design - Choosing among five traditions. Thousand Oaks: Sage Publications.

Engwall, M. (2003). No project is an island: linking projects to history and context. Research Policy, 32(5): 789-808.

Fayol, H. (1918). Administration industrielle et générale, Dunod.

Fitzgerald (1998). An empirically-grounded framework for the information systems development process. Proceedings of the International Conference on Information Systems, Helsinki, pages 103-114.

Ford, J. D. (1999). Organizational change as shifting conversations. Journal of Organizational Change Management, 12(6): 480-500.

Ford, J. D., and Ford, L. W. (1995). The role of conversations in producing intentional change in organizations. Academy of Management Review, 20(3) : 541-570.

Garfinkel, H. (1967). Studies in ethnomethodology. Englewood Cliffs, N.J: Prentice-Hall. 
Garfinkel, H. (2002). Ethnomethodology's program: Working out Durkeim's aphorism. Lanham, Md: Rowman \& Littlefield Publishers.

Goethe, J.W. (1797). The Sorcerer's Apprentice (Der Zauberlehrling).

Gouldner, A. (1973). Organizational analysis. In R.K. Merton, K.Broom and L.S. Cottrell (eds.), Sociology Today, New York, Basic Books.

Gregory, J. (2000). Sorcerer's Apprentice: Creating the Electronic Health Record, ReInventing Medical Records and Patient Care. Ph.D. Dissertation, Department of Communication, University of California-San Diego, La Jolla, CA.

Greimas, A. J. (1983). Du sens: essais sémiotiques. Paris: Éditions du Seuil.

Hassard, J., Kelemen, M., \& Cox, J. W. (2008). Disorganization theory: Explorations in alternative organizational analysis. London: Routledge.

Hatch, M.J. (1997) Organization Theory. Oxford University Press, Oxford.

Heritage, J. (1984). Garfinkel and ethnomethodology. Oxford: Polity Press.

Hobday, M. (2000). The project-based organisation: an ideal form for managing complex products and systems? Research Policy, 29(7-8), 871-893.

Hodgson, D. E. (2002). Disciplining the professional: the case of project management. Journal of Management Studies, 39(6): 803-821.

Hossenfelder, S. (2008). The Spirits That We Called. Available at CiteSeer: http://citeseerx.ist.psu.edu/viewdoc/summary?doi=10.1.1.183.3883 (last accessed on May $28,2012)$.

Jeffcutt, (1994). From Interpretation to Representation in Organizational Analysis: Postmodernism, Ethnography and Organizational Symbols. Organization Studies, 15(2), $241-274$. 
Kuhn, T. R. (2008). A communicative theory of the firm: Developing an alternative perspective on intra-organizational power and stakeholder relationships. Organization Studies, 29(8-9), 1227-1254.

Kuhn, T. R. (forthcoming). The (dis)ordering force of communication: Thought leadership for organization theory. Management Communication Quarterly.

Law, J. (1992). Notes on the Theory of the Actor-Network: Ordering, Strategy and Heterogeneity. Systems Practice, 5 : 379-93.

Law, J. (1994). Organizing modernity. Oxford, UK: Blackwell.

Law, J. (2001) 'Ordering and Obduracy', http://www.comp.lancs.ac.uk/\%20sociology/soc068jl.html.

Law, J. and Mol, A.M. (2002). Complexities: Social Studies of Knowledge Practices, Duke University Press, Durham, NC.

Levina, N., \& Orlikowski, W. J. (2009). Understanding Shifting Power Relations Within and Across Organizations: a Critical Genre Analysis. Academy of Management Journal, 52(4), 672-703.

Lewin, K. (1947).Group decisions and social change. In Newcomb, T. M. and Hartley, E. L. (Eds), Readings in Social Psychology. New York: Henry Holt.

Lewis, J. P. (2002). Fundamentals of project management. $2^{\text {nd }}$ edition, New York: AMACOM.

Lindkvist, L. (2004). Governing Project-based Firms: Promoting Market-like Processes within Hierarchies. Journal of Management \& Governance, 8(1) : 3-25.

Luhmann, N. (1981). The improbability of communication. International Social Science Journal, 23(1), 122-32.

Luhmann, N. (1992). What is communication? Communication Theory, 2(3), 251-259. 
Luhmann, N. (2003). Organization. In: T. Bakken and T. Hernes (Eds.). Autopoietic organization theory: Drawing on Niklas Luhmann's social systems perspective, (pp. 31-52). Oslo: Copenhagen Business School Press.

Lundin, R. A., and Söderholm, A. (1995). A theory of the temporary organization. Scandinavian Journal of Management, 11(4), 437-455.

Manning, S. (2008). Embedding projects in multiple contexts - a structuration perspective. International Journal of Project Management, 26(1), 30-37.

March, J. G. and Olsen, J. P. (1975) 'The Uncertainty of the Past: Organizational Learning under Ambiguity', European Journal of Political Research 3: 147-71.

Morin, E. (1973). Le paradigme perdu: La nature humaine [Paradigm lost: Human nature]. Paris, France: Seuil.

Morin, E. (1986). La méthode 3. La connaissance de la connaissance. Livre premier: Antropologie de la connaisance [Method 3. The knowledge of knowledge. Book One: Anthropology of Knowledge]. Paris, France: Seuil

Nassehi, A. (2005). Organizations as decision machines. Niklas Luhmann's theory of organized social systems. In: C. Jones and R. Munro (Eds.). Contemporary organization theory, (pp. 178-191). Oxford: Blackwell.

Nonaka, I. (1988) Creating organizational order out of chaos: Self-renewal in Japanese firms. California Management Review, 30(3), 47-73.

Packendorff, J. (1995). Inquiring into the temporary organization: new directions for project management research. Scandinavian Journal of Management, 11(4): 319-333.

Parsons, T. (1951). The Social System, Glencoe, Illinois: The Free Press, Pina e Cunha, M., \& Gomes, J. F. S. (2003). Order and Disorder in Product Innovation Models. Creativity and Innovation Management, 12(3), 174-187. 
Ricoeur, P. (1981). Hermeneutics and the human sciences: Essays on language, action and interpretation. Cambridge: Cambridge University Press.

Riemenschneider, C. K., B. C. Hardgrave and F. D. Davis (2002). Explaining software developer acceptance of methodologies: a comparison of five theoretical models, IEEE Transactions on Software Engineering, 28(12): 1135-1144

Robichaud, D., Giroux, H. and Taylor, J. R. (2004). The metaconversation: The recursive property of language as a key to organizing. The Academy of Management Review, 29(4), 617-634.

Schatzki, T. R. (2001). Introduction - practice theory, in Schatzki, T. R., K. Knorr-Cetina, and E. von Savigny (eds). The practice turn in contemporary theory, London: Routledge.

Schatzki, T. R. (2006). On Organizations as they Happen. Organization Studies, 27(12), 1863-1873.

Schoeneborn, D. (2011). Organization as communication: A Luhmannian perspective. Management Communication Quarterly, 25(4) 663-689.

Serres, M. (1982). Hermes: Literature, science, philosophy. Baltimore: The Johns Hopkins University Press.

Shenhar, A. J. and D. Dvir. (1996). Toward a typological theory of project management. Research Policy, 25: 607-632

Shenhav, Y. A. (1999). Manufacturing rationality: The engineering foundations of the managerial revolution. Oxford: Oxford University Press.

Smith, W. K., and Lewis, M. W. (2011). Toward a theory of paradox: A dynamic equilibrium model of organizing. Academy of Management Review, 36(2), 381-403.

Söderlund, J. (2004). Building theories of project management: past research, questions for the future. International Journal of Project Management, 22: 183-191. 
Söderlund, J. (2005). What project management really is about: alternative perspectives on the role and practice of project management. International Journal of Technology Management, 32(3/4): 371-387.

Spee, A. P., and Jarzabkowski, P. (2011). Strategic planning as communicative process. Organization Studies, 32(9), 1217-1245.

Spoelstra, S. (2005). Robert Cooper: Beyond organization. The Sociological Review, 53, 106119.

Stacey, R.D. (1995) The science of complexity: An alternative perspective for strategic change processes. Strategic Management Journal, 16, 477-95.

Staudenmayer, N., Tyre, M., and Perlow, L. (2002). Time to Change: Temporal Shifts as Enablers of Organizational Change. Organization Science, 13(5), 583-597.

Strauss, A. L. (1993). Continual permutations of action. New York: Aldine de Gruyter.

Taylor, F. 1911. Principles of Scientific Management. New York: Harper.

Taylor, J. R. and Robichaud, D. (2004). Finding the organization in the communication: Discourse as action and sensemaking Organization, 11(3): 395-413.

Taylor, J. R., and Van, E. E. J. (2000). The emergent organization: Communication as its site and surface. Mahwah, N.J: Lawrence Erlbaum Associates.

Taylor, J. R., and Van, E. E. J. (2011). The situated organization: Case studies in the pragmatics of communication research. New York: Routledge.

Thiétart, R. A. and Forgues, B. (1995). Chaos Theory and Organization. Organization Science, 6(1), 19-31.

Trethewey, A., \& Ashcraft, K. L. (2004). Special issue introduction. Practicing disorganization: The development of applied perspectives on living with tension. Journal of Applied Communication Research, 32, 81-88. 
Truex, D., R. Baskerville and J. Travis. (2000). Amethodical systems development: the deferred meaning of systems development methods, Accounting, Management and Information Technologies, 10: 53-79.

Tsoukas, H. (1998). Introduction: Chaos, Complexity and Organization Theory.

Organization, 5(3), 291-313.

Tsoukas, H., and Chia, R. (2002). On organizational becoming: Rethinking organizational change. Organization Science, 13(5), 567-582.

Tufte, E. R. (2003). The cognitive style of PowerPoint. Cheshire, CT: Graphics Press.

Tyre, M. J., and Orlikowski, W. J. (1994). Windows of Opportunity: Temporal Patterns of Technological Adaptation in Organizations. Organization Science, 5(1), 98-118.

Walt Disney Picture (Producers) and Algar, J., Armstrong, S., Beebe, F., Ferguson, N., Hand, D. D., Handley, J., Hee, T., Jackson, W., Luske, H., Roberts, B. Satterfield, P. and Sharpsteen, B., (Directors). (1940). Fantasia [Motion picture]. United States: Walt Disney

Weick, K. E. (1977). "Organization Design: Organizations as Self- Designing Systems," Organizational Dynamics, 6, 31-46.

Weick, K. E. (1990). The vulnerable system: An analysis of the Tenerife air disaster. Journal of Management, 16, 571-593.

Weick, K. E. (2001). Making sense of the organization. Oxford: Blackwell

Yates, J., and Orlikowski, W. J. (2007). The PowerPoint presentation and its corollaries: How genres shape communicative action in organizations. In M. Zachry, and C. Thralls (Eds.), The cultural turn: Communicative practices in workplaces and the professions (pp. 67-92). Amityville, NY: Baywood. 
Table 1: Overview of the three case studies

\begin{tabular}{|c|c|c|c|}
\hline & Case 1 & Case 2 & Case 3 \\
\hline Organization & $\begin{array}{l}\text { Explora: a science and } \\
\text { technology diffusion } \\
\text { program of the Chilean } \\
\text { government }\end{array}$ & $\begin{array}{l}\text { Soft-A: a Montreal } \\
\text { software development } \\
\text { company }\end{array}$ & $\begin{array}{l}\text { ABC Consulting: a } \\
\text { multinational business } \\
\text { consulting firm }\end{array}$ \\
\hline Project(s) & $\begin{array}{l}\text { The Science Week } \\
\text { project: Explora's } \\
\text { main national diffusion } \\
\text { event }\end{array}$ & $\begin{array}{l}\text { The Graph project: } \\
\text { rewriting of an } \\
\text { application to create } \\
\text { graphics }\end{array}$ & $\begin{array}{l}\text { IT-based solution } \\
\text { projects for multiple } \\
\text { firms }\end{array}$ \\
\hline $\begin{array}{l}\text { Organizational } \\
\text { ethnography }\end{array}$ & $\begin{array}{l}\text { Video-shadowing of } \\
\text { the project }\end{array}$ & $\begin{array}{l}\text { Ethnographic study } \\
\text { (mainly) based on } \\
\text { observation }\end{array}$ & $\begin{array}{l}\text { Ethnographic study } \\
\text { (mainly) based on } \\
\text { document analyses and } \\
\text { interviews }\end{array}$ \\
\hline Empirical material & $\begin{array}{l}170 \text { hours of video- } \\
\text { recording, } 12 \\
\text { interviews, work } \\
\text { documents }\end{array}$ & $\begin{array}{l}22 \text { meetings, } 25 \\
\text { interviews, } 800 \text { pages } \\
\text { of documents. }\end{array}$ & $\begin{array}{l}565 \text { documents, } 14 \\
\text { interviews }\end{array}$ \\
\hline
\end{tabular}


Figure 1: The proposal form: ordering through table and blank spaces

II. PROGRAM OF ACTIVITIES

1. SPECIFIC ACTIVITIES DEMANDED BY THE PROGRAM EXPLORA

\begin{tabular}{|l|l|}
\multicolumn{1}{|l|}{1.1} \\
\hline Name of the difusion activity & One thousand scientists, One thousand classrooms \\
\hline Date of realization & Tuesday October 3rd 2006 \\
\hline $\begin{array}{l}\text { Participatory public } \\
\text { (People and institutions) }\end{array}$ & \\
\hline
\end{tabular}

Figure 2: Snapshot from document 52, showing how things will appear in the new

\section{Graph window}

2. Les couleurs des sous-ensembles dans

et

Comme on utilise deux séries de couleurs, le fond blanc

\begin{tabular}{|c|c|c|c|}
\hline & & & \\
\hline$\checkmark$ & 18 & 238 & \\
\hline$\checkmark$ & E & 171 & 30 \\
\hline$\checkmark$ & 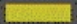 & 168 & 31 \\
\hline$\checkmark$ & 5 & 141 & 53 \\
\hline$\checkmark$ & 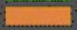 & 227 & 55 \\
\hline$\checkmark$ & & 167 & 92 \\
\hline$\checkmark$ & 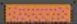 & 168 & 93 \\
\hline
\end{tabular}

Si on est dans les autres graphiques, on verra la série des couleurs pour le fond noir.

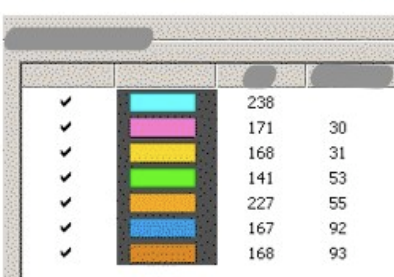

II n'y a rien qu'on peut faire à ce niveau. Notez que la fenêtre n'est pas

modale, si on a déjà ouvert cette fenêtre et on change de mode de graphique, la couleur dans cette fenêtre ne suit pas le graphique à l'arrière.

On ne peut pas non plus modifier la couleur de fond dans ces fenêtres, les couleurs sont toujours présentées sur un fond noir. 
Figure 3: Example of a “polished” PowerPoint slide from our data

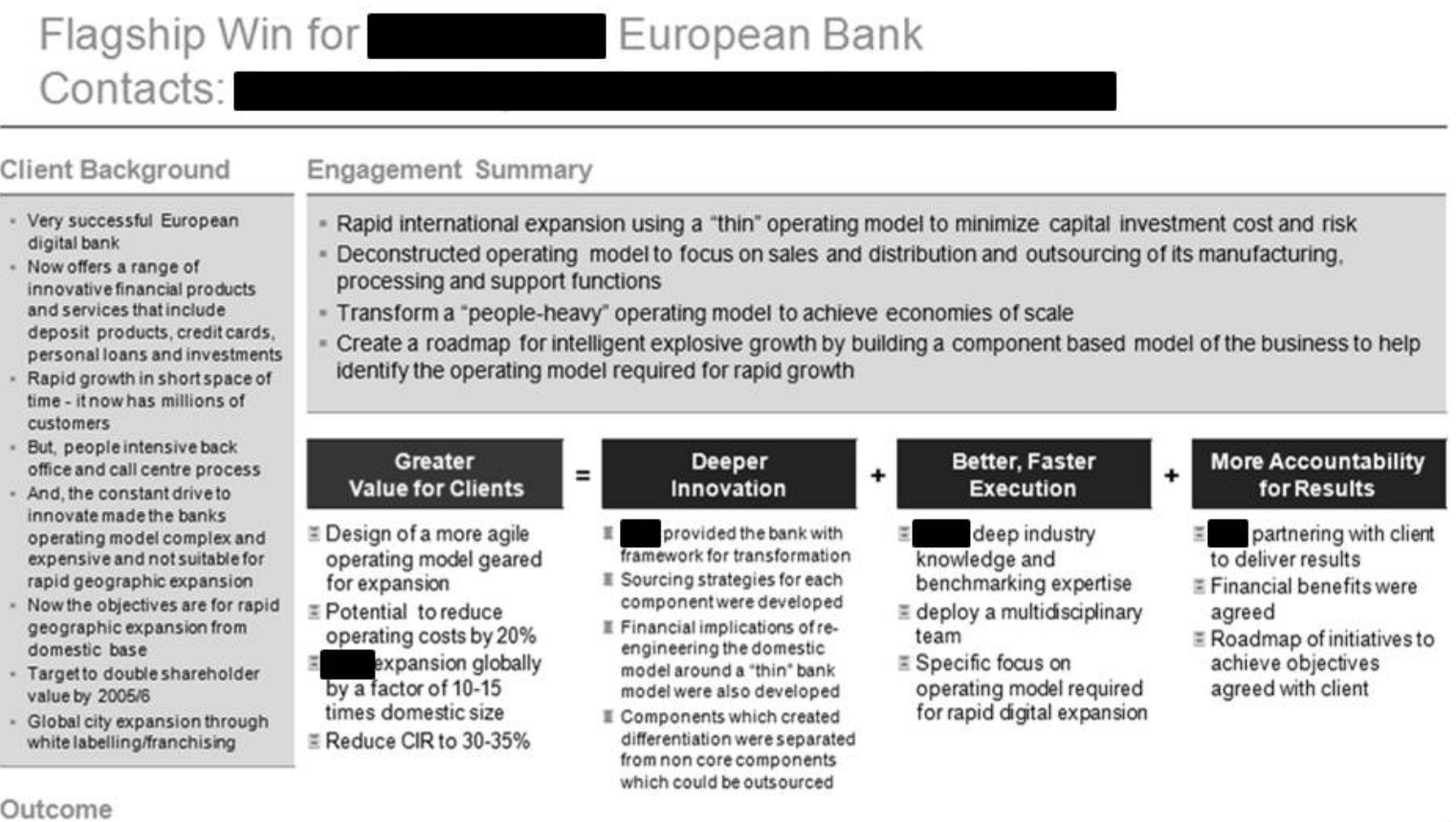

- Variable: Outsourcing all non core activities reduces capital requirements for explosive expansion and creates opportunities to change
to change fixed costs to variable costs
- Responsive: Bank's management team to focus on customer service and innovating new financial products
- Focused: The outsourcing of all non core activities allows bank to focus on its key differentiators of sales and distribution
- Resilient: Resilience can be achieved by using partners who provide "best in breed" technology solutions

Table 2: Comparative analysis of the three cases

\begin{tabular}{|c|c|c|c|}
\hline & Case 1 & Case 2 & Case 3 \\
\hline order/disorder & order/removing & disorder to re-order & Attempting to create \\
& local, polished order (the & project) on the expense \\
& & & Acknowledging \\
& & & (across projects) \\
\hline (Dis)ordering & Proposal form & Technical template & One-slide Power Point \\
device & & & presentation \\
\hline Language-use & Blank space & Statements of closure & Ellipsis \\
\hline
\end{tabular}

